\title{
REGRESSÃO CAPITALISTA NO BRASIL
}

\author{
Jurandir Antônio Xavier \\ Professor Titular em Economia da UFPb
}

\section{RESUMO}

A industrialização "terceiro mundista" que aqui ocorreu não foi um "produto natural" do desenvolvimento capitalista, nem a realizaçâo de algum "projeto burguês capitalista", operacionalizando-se sob iniciativa, conta e risco privado-capitalistas. Ao contrário, aqui, seu desenvolvimento mais significativo deu-se sob superação específica dos capitais, das classes enriquecidas e do próprio "curso natural" do capitalismo, agro-oligárquico-comercial. Superação que se processou sob estatizaçào deficitária de funções capital-produtivas (monetário-financeiras, produtivas propriamente e comerciais), desenvolvimentistas, sob iniciativa, conta e riscos estatais, formalmente sociais. Deflagrada a crise de tais relações Estado-Economia, agonizando-se Estado, economia e desenvolvimento das forças produtivas, a iniciativa privado-capitalista, supercapitalizada, lançou-se preferencialmente aos mercados especulativos. Com isso, a regressão capitalista ganhou curso livre, cotidianizando a barbárie.

\section{CONJUNTURA REGRESSIVA}

No Brasil $^{(1)}$, regressão capitalista veio a significar desindustrialização: conjuntura de crise, recessão ou depressão, experimentada com a bancarrota das relações estatal-capitalistas de produçào, apropriação e uso da riqueza social. Tais relações entrè Capital e Estado (Capital), e, entre Capital e Trabalho marcaram o periodo mais significativo do desenvolvimento das forças produtivas na economia brasileira, subdesenvolvida: o da industrialização. Porém, tais

(1) XAVIER, Jurandir António. Texto originário da Tese de Habilitação, Ciclo de Conjuntura na Economia subdesenvolvida, apresentada na UFPb, Campina Grande 1993. 
relações foram à bancarrota, assim como o próprio Estado em suas funções capital-produtivas, desenvolvimentistas, sob "fustigamento" da privatização, centralização capital-financeira. Com isso, a economia nacional veio a ter seu "destino" entregue sobretudo à iniciativa privado-capitalista, .e, mediante extensão da capitalização financeira, especulativa, conheceu sua desindustrialização: sinônimo de descapitalização produtiva, desemprego e pauperização social. Esta conjuntura socialmente regressiva, aberta ao iniciar a década de oitenta, ainda hoje não foi debelada, estendendo-se aos anos noventa ${ }^{(2)}$.

Convém ter em conta que, aqui, economia subdesenvolvida,o capitalismo evoluiu preponderantemente nas atividades agro-comerciais, originadas em torno da internacionalização do próprio capitalismo, suas mercadorias, seus mercados comerciais e seus métodos de enriquecimento. $O$ desenvolvimento capitalista das forças produtivas especificamente industriais acabou não se mostrando capital-compensador, rentável ou lucrativo. Com isso, o desenvolvimento das forças produtivas na economia nacional, sua industrialização, não se deu sob a lógica especificamente capitalista, lucro. Isto significa que aqui a industrialização não se fez expansiva no curso natural, normal ou lógico do desenvolvimento capitalista, nem se fez sob relações especificamente capitalistas de produçâo, apropriaçào e enriquecimento privado, nem muito menos sob iniciativa, conta e risco privado-capitalistas.

Ao contrário, o desenvolvimento das forças produtivas, sua industrialização numa dimensão macroeconomicamente significativa, veio a ter curso acelerado, aqui na economia subdesenvovida, apenas sob superação específica do capitalismo no próprio capitalismo. Superação negativa (formal, parcial e conjuntural) de classes, riqueza e usos que delas foram feitos, no processo de mutação do Estado, (destinos, usos è funções de suas finanças) em agente capital-produtivo,

\section{(2) XAVIER, Jurandir Antônio; Regressão Versus Desenvolvimento.} Gráfica/Editora A União, Joāo Pessoa, 1992. Do mesmo autor, ver "A Regressão Social Sob a Privatização Contemporânea". Revista "Novos Rumos" $N^{\circ}$ 18/19, pg. 72. Sāo Paulo, 1990. Ver Também Capital, Classe e Estado na Industrializaçāo Nacional, (no prelo da Editora Universitária, UFPb). 
desenvolvimentista. Tal mutação veio a significar estatização deficitária de funções capital-produtivas no ciclo econômico-industrial: funções monetário-financeiras, produtivas e comerciais. Assim, nessa específica "divisāo do trabalho", na qual os agentes estatais foram lançados à produçào deficitária de mais-valia, enquanto os capitalistas à apropriação superavitária, o Estado foi tensionado à bancarrota capital-desenvolvimentista, sobretudo ao ser aprisionado aos movimentos de valorização do capital financeiro, inativo ${ }^{(3)}$.

De um lado, os agentes privado-capitalistas foram supercapitalizados; de outro, o Estado foi exaurido em sua capcidade de gastos capital-produtivos, bem como a força de trabalho em seu poder de compra, e o que é significativo: os agentes privado-capitalistas năo reconverteram produtivamente suas riquezas acumuladas, "socorrendo" ou fazendo superar a conjuntura da crise. Ao contrário, tais agentes entregaram rapidamente suas fortunas acumuladas à própria valorizaçào especulativa, nacional ou internacional. De tal forma que, na amplificação das ações especulativas dos agentes privado-capitalistas, expansão do endividamento do Estado e extensão da barbárie social no cotidiano deste país, a crise ganhou curso livre. Nào contando o país com riquezas capitalistas reinvestidas produtivamente, nem contando com o poder de compra da força de trabalho e seus gastos de consumo: e ainda com o Estado inutilizado como reserva estratégica da regulaçãc cconômica, em atividades anti-ciclica (contrapositiva às capital-espcculativas, fonte de intensificação da crise), então, a crise veio a scr agravada, metamorfoseando-se em recessão, depressão e regreșão das forças produtivas.

\section{RAZÕES DA CONJUNTURA}

As funçòcs capital-produtivas não mais lograram ser expandidas às custas de déficits do Estado, não mais logrando ser expandidos estatal-deficitariamente, mediante iniciativa, conta e risco estatal-sociais, rcinvestimento, produçào e mercado nacional, numa dimensão

(3) FURTADO, Celso; Formação Econômica do Brasil. Companhia Editora Nacional; Sào Paulo, 1970. Também, Formaçāo Econōmica da América Latina, Companhia Editora Nacional, 1970. 
macroeconomicamente signficativa. Desmonoradas as relações estatal-capitalistas, cessou-se o desenvolvimento das forças produtivas. E, nestas circunstâncias, reinvestimento, produção e mercado não mais são expandidos, ao contrário, regridem, tendendo a se amplificarem as tensões nas relações estatal-capitalistas de propriedade, produção e apropriação em crise: as relações capital-Estado, na concorrència capitalista, e, capital-trabalho, nas lutas de classes.

Com o desmoronamento das relações estatal-capitalistas que deram suporte, via expansão deficitária de reinvestimento, produção e mercado, ao desenvolvimento das forças produtivas, este se retrai. $O$ capital produtivo e o emprego da força de trabalho não mais se expandem numa dimensão macroeconomicamente significativa, nem quanto ao volume de ocupação da força de trabalho, nem quanto a sua produtividade. Ao contrário, de um lado, o componente constante do capital produtivo não é expandido, nem renovado, é sucateado. De outro lado, seu componente variável, força de trabalho, é contraído, vindo a ser reduzido, quanto a volume e quanto á produtividade da força de trabalho ocupara. Não se reconstitui uma nova combinação de relaçōes social-capitalistas de produção, sob formas de socialização das condições de produção, superiores às estatais precedentes. Dai o desmoronamento das relações de produção não vem a ser superado. Tão pouco o desenvolvimento das forças produtivas volta a ser retomado significativamente, ocorrendo, ao contrário, o enriquecimento financeiro, especulativo e parasitário. Estende-se, assim, a crise da reprodução, retraindo reinvestimento, produçào e mercado, agravando a concorrência capitalista, bem como reduzindo emprego, salário e poder de compra, agravando as lutas de classe.

Por conseguinte, as características esscnciais não são as decorrentes da crise clássico-recessiva, ciclica, normal ou conjuntural, no âmbito das próprias relaçôes estatal-capitalistas, mas as da conjuntura regressiva. Marcam essencialmente tal conjuntura as características decorrentes da metamorfose da recessão $\mathrm{cm}$ depressao, regressão e desindustrialização, que se impôs na economia nacional, na extensão, tanto do esgotamento, falência e bancarrota das próprias relações estatal-capitalistas, sobretudo do Estado, scus agentes 
capital-desenvolvimentistas, quanto do parasitismo especulativo, privado-capitalista. Isto significa que, acentuado o capital-parasitismo na crise das relações estatal-capitalistas, ocorreu também o colapso da específica combinação de relações Capital-Estado, em que o capital desapropria o Estado, bem como Capital-Trabalho, em que o capital superexplora a força de trabalho. Nesta combinação, a economia nacional, subdesenvolvida, havia conhecido sua estatal-industrialização. Durante toda uma época histórica, com a emergência do Estado Novo, industrial-desenvolvimentista e com a superação da República Velha, agro-comercial-oligárquica, tais relaçôes haviam dado suporte à industrialização da economia nacional. Não obstante, agora, desde a abertura da década dos anos oitenta, não mais lograram dar sustentação ao desenvolvimento das forças produtivas, vindo a dar, ao contrário, suporte a seus opostos: os movimentos especulativos das riquezas privadamente acumuladas, intensificando ainda mais: bancarrota do Isstado desenvolvimentista, superexploração do trabalho e desindustrializaçào.

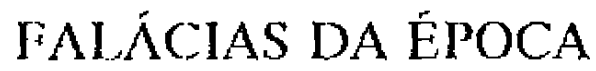

$\mathrm{Na}$ verdade, com o esgotamento do Estado e de suas açôes capital-produtivas, desenvolvimentistas, também se esgotou aquela especifica socialização de propriedade, produção e apropriação da riqueza social, a estatal-capitalista. Em sua ocorrência, a produção da riqueza social, suas funções capital-produtivas, deficitárias, vieram a ser estatizadas, enquanto a apropriação da riqueza social, superavitária, se manteve privatizada. Estas relações estatal-capitalistas não foram superadas positivamente por outras relaçôes sociais de propriedade, produçào e apropriação, distribuição da riqueza gerada, social-historicamente superiores às estatal-capitalistas, em crise. Vieram a ser regredidas, numa específica relação desestatização-privatização. $O$ capital acumulado privadamente não veio a ser reconvertido capital-produtivamente, ao contrário; veio a se tomar financeiro, especulador e parasitário, rentista do Estado. Não se encarregando mais somente do déficit do capital produtivo, sustentando também sua rentabilidade extra, o Estado, incumbindo-se adicionalmente da rentabilidade extra do capital parasitário, acabou sucumbindo. Por isso 
mèsmo, sem reinvestimentos privado-capitalistas, nem estatais, a economia veio a experimentar a intensificação do enriquecimento privado-capitalista, financeiro, especulativo e parasitário. Do mesmo modo, experimentou também a desindustrialização, o rápido sucateamento do capital produtivo, sobretudo dos serviços essenciais, e o agravamento do desemprego.

A atual conjuntura de desindutrialização ilustra o fiasco econômico-social-desenvolvimentista da chamada "iniciativa privada" no Brasil. Subsidiada pelo Estado em suas funções capital-produtivas, industrializada, a reprodução capitalista não logrou se manter de forma auto-sustentada, com iniciativa, risco e conta privado-capitalistas. De um lado, emprego, salário e poder de compra da força de trabalho industriais não vicram a ser expandidos numa tal dimensão que a força de trabalho se constituísse em agente económico e consumidor significativo. $\mathrm{Na}$ verdade, o Estado, suas finanças, encomendas ou gastos vieram a se constituir em mercado consumidor nacional. Com isso, o Estado, suas funções capital-produtivas, vieram a se constituir em agentes ou vias de concentração de renda. A evolução da concentração de renda foi sendo acentuada proporcionalmente à própria estatização dos mercados financeiro- espcculativos. À proporção em que o Estado foi assumindo a valorização financeira, estatizando. funçôes capital-especulativas, via sustentação da rentabilidade de scus papéis, deixou de promover a extensào, renovação e modernização do capital estatal, sobretudo daquela parcela sob forma de serviços públicos essenciais, relegados insensatamente ao sucateamento.

De outro lado, os capitais gerados, apropriados c acumulados, tornados propriedade privado- capitalista, não foram aqui reconvertidos produtivamente, numa dimensão macroeconômica, significativa. Ao contrário, persistiram em se manter financeiros, inativos e parasitários, capitais rentistas do Estado. Com isso, aquela clássica controvérsia nos países subdesenvolvidos, acerca da incapacidade capital-desenvolvimentista de suas burguesias nacionais vir a industrializá-los, dando-lhes rumos industriais, capital-competitivos, no mercado mundial, fica uma vez mais fortalecida. Assim, no Brasil, nos 
meados dos anos sessenta, tal burguesia nacional veio a ser perfilada ao militar-imperialismo, com ele se associando na obtenção de vantagens estatais: financiamentos gratuitos, compras subfaturadas ou vendas superfaturadas. $\mathrm{Na}$ década de oitenta, tanto quebrado econômico-financeiramente o Estado, quanto supercapitalizada tal burguesia, seus capitais não vieram a ser reinvestidos produtivamiente no país, socorrendo uma conjuntura de crise que se degenerava rapidamente, tomando-se, então, regressão, desindustrialização. Eles foram levados aos mercados financeiro-especulativos, nacionais, tornando-se, num primeiro momento, rentistas do Estado nacional, e, adicionalmente, num segundo momento, migrando para os mercados internacionais. Por isso mesmo, a conjuntura recessiva veio a ser metamorfoseada em regressiva, desindustrializante, abrindo campo, por conseguinte, para o sucateamento dos capitais produtivos, sobretudo estatais, neles, os serviços públicos essenciais, bem como para o desemprego, a supexploração e as relações sociais exterminativas.

A intensificação da privatização financeira não foi identificada como fonte retroalimentadora da mutaçâo da recessão em regressào, desindustrialização e estagnação, mas por pressuposto da superação da crise, inclusive de recuperação econômica. Com isso, vieram a entrar em colapso a política econômica (normatização da atividade econômica do Estado), bern como a capacidade de ação anti-cíclica do Estado, contraposição de ações capital-produtivas, desenvolvimentistas, dos agentes estatais, às ações capital-especulativas, parasitárias, dos agentes privado-capitalistas. Sob tal bancarrota da lógica estatal, num cotidiano exteminativo em que a barbárie e a tragédia vieram a ser banalizados, impôs- se a razão liberal, "salve-se quem puder". Os próprios padròes privado-capitalistas de partilha da renda nacional vieram a ser rompidos levianamente. Por isso mesmo, gritos de ética, decência e probidade no trato da "coisa pública" passaram a ecoar em todos os quadrantes, tomando-se reivindicação de massa.

\section{MARCAS DA REGRESSÃO}

Capitalismo, modalidade historicamente determinada de enriquecimento privado, processa-se ampliadamente via apropriação 
de renda nas relações intercapitalistas capital- capital (lutas concorrenciais). Tal renda origina-se da apropriação gratuita de trabalho alheio na produção capitalista, nas relações capital-trabalho (lutas de classe). Tais relações sociais e os métodos de enriquecimento que lhes são subjacentes, na economia subdesenvolvida, vieram a ser especificamente constituidos. Nas relaçôes concorrenciais, devem ser destacadas, num primeiro momento histórico, aquelas especificidades que se fizeram presentes nas relaçòes capital internacional-nacional. Tais relaçōes foram aquelas que, promovendo a agrarização, cercearam a industrialização. Mas também fizeram-se presentes nas relaçōes entre imperialismo, internacionalização da mercadoria industrial e subdesenvolvimento industrial ou ainda entre indústria e agricultura. Num segundo momento, devem ser destacadas aquelas especificidades que se fižeram presentes nas relações capital-Estado, notadamente, cntre privatização da renda e estatização da produção, entre especulação privado-capitalista e produção estatal ou entre parasitismo privado-capitalista e desenvolvimentismo estatal.

Nas relações capital-trabalho, nas lutas de classes que se processam na produção capitalista de mais- valia, devem ser destacadas aquelas especificidades que aqui acabaram tornando tais relações "anormais", superexploradoras ou exterminativas da fora de trabalho. Isto, relativamente ao que seria reproduçào normal da fora de trabalho, a excmplo daquela que se dá nos países mais desenvolvidos. Sem se elevarem significativamente o emprego, o salário e o poder de compra, o detentor da força de trabalho não veio a ser constituido em cidadão, consumidor, nem o mercado, interno ou nacional, veio a tornar-se um " consumidor massivo, significativo. Ao contrário, o mercado nacional acabou sendo estatizado. Nele, a população trabalhadora, scu poder de compra, sua demanda ou scus gastos de consumo, não vieram a se constituir em fonte de atração significativa das riquezas privado-capitalistas em direção ao reinvestimento capital-produtivo. A isto destinaram o Estado, seus gastos.

Tais características das relações capitalistas de apropriação e produçào da mais-valia no país impregnaram de especificidades o próprio enriquecimento privado-capitalista, scus métodos de 
reprodução ampliada e relações sociais. De um lado, tomaram específicas as relações capitalistas de propriedade (fonte de renda), cuja concentração abusiva acabou se constituindo em fonte decisiva de clevação da concentração de renda no país. De outro lado, também conformaram especificamente as relações capitalistas de trabalho, cujo desemprego massivo acabou se constituindo em fonte de salário. Nestas circunstâncias, enriquecimento privado-capitalista tem sido aqui centralização capitalista de renda oriunda de uma forma de propriedade capitalista, capital-produtiva, metamorfoseada numa outra forma de propriedade capitalista, a capital-financeira, parasitária. Isso ocorreu num primeiro momento, época pré-Estado Novo, mediante centralização imperialista, em segunda mão, da riqueza nacional extorquida do trabalho. E, num segundo momento, pós- Estado Novo, mediante centralizaçào privado-capitalista em segunda mão đa riqueza estatal, gerada na propriedade estatal, extorquida do trabalho.

Isso significa que o enriquecimento privado-capitalista veio a adquirir aqui uma dupla determinação desapropriativa (formal e substancial). Tal determinação resultou numa desapropriação capitalista financcira, de um lado, do próprio capital produtivo, de outro, da força de trabalho. Exatamente por esta dupla determinação, a força de trabalho acabou se tornando superexplorada ao nivel exterminativo. Porque, na centralização capitalista, sob a qual se formam os "novos ricos" neste país, as frações capital-desapropriadas dispõem, como mecanismos compensatórios da desapropriação capitalista em que se encontram submetidas, exclusivamente daqueles que geram elevação da renda, via superexploração da força de trabalho no próprio país.

O parasitismo das riquezas aqui acumuladas sob propriedade privado-capitalista não se restringe a seus métodos de acumulação, a suas relaçôes capital-apropriativas. Ele se estende aos movimentos preferenciais, ao próprio destino, uso ou funções que tais riquezas. adquirem sob iniciativa privado-capitalista. Estendem-se aos mercados financeiro-especulativos. Por isso mesmo, os problemas da continuidade da reprodução capitalista, do "desenvolvimento auto-sustentado" ou problemas da superação das crises periódicas, da retomada do desenvolvimento, após cada crise, também mostraram-se 
muito específicos. Tais dilemas, aqui, ocorriam apenas na constituição de novos agentes econômico-sociais, lançndo-se a atividades capital-produtivas. Assim, cada novo ciclo de desenvolvimento, recuperação, expansão e auge econômicos, apenas veio a ser desencadeado através de tal constituição que se mostrou, na verdade, reconstituição do próprio Estado e de suas funções capital-produtivas no ciclo econômico. Isto, enquanto o Estado logrou reciclar suas atividades monetárias, produtivas e comerciais, reconstituindo sua capacidade de financiamento, reinvestimento e gasto capitalprodutivos, periodicamente neutralizada nas crises. Então, também a conjuntura de crise lograva vir a ser superada, abrindo caminho a novos ciclos de reinvestimentos capital- desenvolvimentistas.

\section{A CONJUNTURA NA HISTÓRIA}

A periodização de que se trata aqui é a do enriquecimento privado-capitalista, de scus métodos característicos de centralização, apropriação e acumulação privado-capitalista, métodos capital-parasitários que se mostraram desapropriadores do próprio capital, sobretudo produtivo e estatal. Trata-se também da periodização dos métodos característicos de produção social de renda, riqueza nova ou mais-valia, a partir de extração de mais-valia da força de trabalho em niveis exterminativos. Se apropriação, acumulação ou enriquecimento privado-capitalista aqui correspondem à recentralização de rendas capitalistas, oriundas da propriedade capital-produtiva, desenvolvimentista, para a propriedade financeira, parasitária, então, no desenvolvimento capitalista deste pais, sobretudo, em sua industrialização, há dois momentos decisivos na periodização capital-desenvolvimentista aqui apresentada. Aquele em que prevaleceu a apropriação capital-estatal da riqueza social, gerada preponderantemente da propriedade estatal e do trabalho super-explorado. Por esta via, o Estado logrou sustentar funções capital-produtivas estatizadas, deficitárias, conhecendo o país seu periodo de industrialização mais significativo. Ele correspondeu ao periodo que decorreu da instauração do Estado Novo, na bancarrota da República Velha, à bancarrota da República Janguista. No segundo momento, veio a prevalecer a apropriação privado-capitalista, 
financeira, parasitária e rentista do Estado, cuja evolução persistiu durante as duas últimas décadas, vindo a quebrar econômico-financeiramente os principais agentes capital-produtivos desenvolvimentistas no país, o Estado e a força de trabalho. Com isto, a economia nacional veio a conhecer sua privado-financeirização, especulativa, à custas, não obstante, de sua desindustrialização e barbarização social.

Por conseguinte, ao iniciar a década de oitenta, encerrou-se a conjuntura de auge da industrialização, abrindo-se a conjuntura de crise do estatal-capitalismo, sua desindustrialização, regressão e ocaso. Do mesmo modo, surgiu a abertura da conjuntura de auge da financeirização, intensificando-se a capitalização privado-financeira às custas da descapitalização capital-produtiva, estatal. As curvas dos reinvestimentos capital-produtivos (capitalização estatal-industrial) e capital-financeiros (capitalização privado-financeira) marcham defasadas em noventa graus.

A curva de formação do capital-financeiro nacional (bem como da desestatização-privatização), desindustrializando, não precede, ao contrário sucede à curva dos reinvestimentos produtivos, que industrializam.

Contrariando as principais escolas capital-desenvolvimentistas no país, o capital financeiro nacional (formado numa específica relação de privatização financeira, estatal-desapropriadora), não foi pré-condição de suporte da industrialização, mas seu resultado, seu "estrangulador"(4). Por isso mesmo, também a desestatização-privatização não veio a ser pressuposto da superação da crise do estatal-capitalismo nem da retomada do desenvolvimento. Ao contrário, inativo, parásitario e rentista do Estado, o capital financeiro nacional, bem como as relaçôes de desestatização-privatização que lhe deram suporte, contribuiram para intensificação da crise, levando o 
capital produtivo, sobretudo estatal, ao sucateamento, a força de trabalho ao extermínio e o país à barbárie social cotidianizada.

(4) MELLo, João Manuel Cardoso de. o Capitalismo Tardio. São Paulo, Brasiliense, 1982. Ver também Maria da Conceição Tavares, Acumulaçào de Capital e Industrialização no Brasii. Campinas, Editora Unicamp, 1986. 